\title{
Slip of the Pen as A Psychopathology of Everyday Life on Wilde's Happy Prince and OtherTales
}

\author{
Mutmainnah $^{1}$, Ansor Putra ${ }^{2}$, Eva Solina Gultom ${ }^{3}$ \\ \{mutmainnaha@gmail.com ${ }^{1}$, ansor.putra@gmail.com ${ }^{2}$, eva_joshgroban@yahoo.com ${ }^{3}$ \} \\ ${ }^{123} \mathrm{Halu}$ Oleo University Kendari, Sulawesi Utara
}

\begin{abstract}
Oscar Wilde is recognized for his tragedy and supernatural short stories as one of his astonish works, The Black Cat, still discussed in this very modern day. In 1888, Wilde then succeeded to make a move of his work by the publication of his collection entitled The Happy Prince and Other Tales. The collection consists numbers of the stories; The Happy Prince, The Nightingale and The Rose, The Selfish Giant, and The Devoted Friends. Considering seven works in ne collection, it is possible that Wilde himself did a slip of the pen among his works in a collection. This study aims to find a slip of the pen in Wilde's collection The Happy Prince and Other Tales, and to analyze the construction and the effect of the slip through his collection as well. In analyzing the occurrence of the slip, the study uses the psychopathology of everyday life, one of the remarkable theories of Freud. This study finds that Wilde, in fact, did two kinds of slip of the pen such realization on his writing and meaning repetition. For the realization, it could be find on his first story where he actually wanted to show the great sense of love and kindness in The Happy Prince, but ended the story by shading the love itself with 'little better than a beggar'. For the meaning repetition, it appeared on his idea on love as a silly thing on the second to the fourth story.
\end{abstract}

Keywords - Short Story, Slip of the pen, Psychopathology of everyday life, Oscar Wilde.

\section{Introduction}

"Is literature a special kind of language or is it a special use of language? Is it language organized in distinctive ways or is it language granted special privileges?"

This opening statement from Culler [1] in his A Very Short Introduction Literary Theory brings literature scholars to the further question, how the author creates a literary works? But there will be no discussion related what is literature in this study or is it important to discuss about, instead of understanding it. This study straightforwardly takes one kind of literary works, short stories. How short stories built by the author and how are it possible to relate the symptoms that the readers found by their readings to one of the literary theories that they thought it might have something to do within. The interpersonal fond of psychoanalysis and psychopathology of everyday life by the researcher then brings this writing to try to relate what 
might happen on Wilde that affected his writing in Happy Prince and Other Tales collection that published in 1888 .

Based on the previous studies, it could be said that to find a study on slip of the pen is actually pretty hard for most people using the Freud's lip of the tongue on everyday life. Let say on what Haslam [2] said on his Freudian Slip? A Changing Cultural Fortunes of psychoanalytic Concepts that focus on the slip of the tongue and how it appears on the cultural life of people. Another study about Freudian slip is from Alder's [3] Slip of the Tongue as Opportunity for Empathy the Reversed Directedness of 'Project' by A Patient and Her Therapist. On his writing, the concept of Freudian slips that again, focus on the slip of the tongue that happened on the patience and how to respond their slips. It is pretty much the same with what Skues [4] said on his On the Dating of Freud's Aliquis Slip that discuss only on hot to sinking into the Freudian slip's concept. As stated before that most of the studies related Freudian slip are focusing the analysis on the slip of the tongue, like Sharpe [5] also published his paper entitled To Slip, perchance to Dream; Freud on the Unconscious, which shows how the slip is actually steered by people's unconsciousness when it compared to the concept of dream and Dimen [6] on his Lapsus Linguae, or A Slip of the Tongue? that also focusing his analysis on slip of the tongue in everyday conversation.

From the previous studies, it shows that the study of the slip of the pen, as one of the types of Freudian slips. That is one of the strong reasons the author then chose to analyze the slip of the pen on a collection of short story that the appearance of the slip of the pen is likely to occur. Back to what Culler said before, 'is literature a special kind of language or is it a special use of language' (that implied by the author)? One exactly thought that literature is written based on the language structured in the author's mind that might has a mixture of what was the author is thinking and feeling on the moment he wrote the literature itself. 'Is it language organized in distinctive ways or is it language granted special privileges?' leads the researcher to think back what Bakhtin [7] said that the author is actually trying to hiding his true tendency in his writings by pulling out himself from the writing itself. When the author is entirely focusing himself in separating his true tendency to what he wants the reader finds, he might likely unconsciously reveal his true in, let say, a slip. To prove this initial thought and by the mixture of author's tendency in writing a literature leads the researcher to study the psychopathology of everyday life in Wilde's Happy Prince and Other Tales collection by having it to and fro in order to find the signs and the symptoms related on. The main purpose of the study is to show the concept of the slip of the pen that actually has various kinds of symptoms and how to intertwine it each other and analyze it using the Freudian concept of unconsciousness and slip itself.

\section{Method}

This is a psychoanalysis study using the psychopathology of everyday life by Freud. The method of collecting the data is by reading the Wilde's collection The Happy Prince and Other Tales and various sources related Oscar Wilde, psychoanalysis, and psychopathology of everyday life. In general, the method of collecting data are reading, coding, connecting to the sources, and categorizing. Meanwhile, the method of analyzing the data is using the psychoanalysis of the author approach from his writing through the theory of psychopathology of everyday life; the slip of the pen. In reading, the researcher should be very careful in scrutinize the word by word used by the author in his collection. Put the focus more on the 
repetition that used by the author, especially when it comes to the very close line and use such exclamation, for there is a repetition case of the slip of the pen. Moreover, in analyzing the data, the researcher also need to be focus on the each story and how it ended by the author. What story comes next after one and find the link that intertwine each story. It usually appears on the end of the story of each.

\section{Result and Discussion}

'The slip of the pen needs no explanation: its interpretation is perfectly plain"

In his psychopathology of everyday life, Freud said as one of the typical slip of the pen as he told a story of the telegram for Vienna which appeared in the paper on October 11, 1081; in view of the complete mutual confidence which has prevailed between ourselves and our German allies throughout the war, it may be taken for certain that the two Powers would reach unanimous decision in all circumstances. It Is unnecessary to state specifically that active and interrupted co-operation between the allied diplomatists is taking place at the present stage as well. Only a few weeks later it was possible to express one's opinion more frankly about this 'mutual confidence', and there was no longer any need to take refuge in a slip of the pen (or misprint).

We have every reason to suppose, too, that the very frequent repetition of the same word in writing and copying - 'perseveration' - are likewise not without significance. If the writer repeats a word he has already written, this is probably an indication that it was not easy for him to get away from it; that he could have said more at that point but had omitted to do so, or something of the kind. Perseveration in copying seems to be a substitute for saying 'I too'. [8]

In this case, Wilde might not be in the case of repeating his word in these seven stories in one collection. He is more like repeating the concept of love, which is more a silly thing instead of something with pure affection.

In the first story, The Happy Prince, Wilde sensed tried to move his effort to show the greatness of the character, the Happy Prince, through his characteristic which is generous by giving all his treasure in his statue to be given to the poor. Meanwhile, there also another character, the Swallow, occurs also as a generous character who decided to stay and deliver the treasure of Happy Prince to the poor. As this story happens to be the first, reader would find the emotion of the great love and pure affection and kindness. But at the end of the story, Wilde put the statement from another character to alter the perspective of the reader on how a great love and kindness could affect the Happy Prince as quoted below;

"How shabby indeed!" cried the Town Councillors, who always agreed with the Mayor; and they went up to look at it.

"The ruby has fallen out og his sword, his eyes are gone, and he is golden no longer," said the Mayor, "in fact, he is little better than a beggar!"

"Little better than a beggar," said the Town Councillors. (20-21)

There is a repetition of 'little better than a beggar' that makes the reader then consider why Wilde put the repetition on this, in line, very close. Is it because it is not easy for Wilde to got rid from the images of little better than a beggar as the result of Happy Prince's love and kindness to the poor?

On the second story, The Nightingale and The Rose, Wilde seemed bravely to straightly put "What a silly thing Love is," said the student as he walked away. "It is not half as useful as logic, for it does not prove anything, and it is always telling one of things that are not going to 
happen, and making one believe things that are not true. in fact, it is quite unpractical, and, as in the age to be practical is everything, I shall go back to Philosophy and study Metaphysics."(34). When it links to what Freud said related one kinds of the slip of pen's symptoms, Wilde, after tried to softly express the bad result of being love and kind to other as 'little better than a beggar', seemed with no hesitation to straightly said 'What a silly thing Love is' and frankly explained in the right-after sentence the reason why the character thought that Love is a silly thing.

From the simple yet clear statement found in the second story, another explanation related the silly thing about love lays also in the third story, The Selfish Giant. The story told about the very selfish giant, who never let anyone to play in his garden, but someday changed his mind and started to open his garden for children to play. At the end of the story, the last conversation between the giant and the beloved child quoted below:

"Who hath dared to wound thee?" cried the Giant; "tell me, that I may take my big sword and slay him."

"Nay!" answered the child; "but these are the wounds of love."

"Who art thou?" said the Giant, and a strange awe fell on him, and he knelt before the little child.

And the child smiled on the Giant, and said to him, "You let me play once in your garden, to-day you shall come with me to my garden, which is Paradise."

And when the children ran in that afternoon, they found the Giant lying dead under the tree, all covered with white blossoms.(43)

In this third story, Wilde gave another frank and clear explanation on how love is not logic and silly from the chronicle of the Giant that should be dead as the result of his generous to let the children play in his garden. Meanwhile, in Wilde's forth story, The Devoted Friend, a story that anyone who reads will build a wrath on how Wilde created the silly thing of Mr. Miller, who asked for so much things from a friend, Little Hans, just because he will be generous to give his wheelbarrow. From one kindness - giving the wheelbarrow - to Little Hans, Mr. Miller then thought that he deserves so much things such to take all the flower of Little Hans, to make Little Hans to repair his barn, to bring the goods, and to go to the doctor to take medicine which this last order from Mr. Miller then kills Little Hans in the middle of the night on a very bad rain. Look at this one of conversations among Mr. Miller and Little Hans quoted below:

"Dear Little Hans," said the Miller, "would you mind carrying this sack of flour for me to market?"

"Oh, I am so sorry," said Hans, "but I am really very busy to-day. I have got all my creepers to nail up, and all my flowers to water, and all my grass to roll"

"Well, really," said the Miller, "I think that, considering that I am going to give you my wheelbarrow, it is rather unfriendly of you to refuse."

"Oh, don't say that," cried Little Hans, "I wouldn't be unfriendly for the whole world"; and he ran in for his cap, and trudged off with the big sack on his shoulders. (56)

When we come to mistakes in reading and writing, we find that our general approach and our observation in regard to mistakes in speaking hold good here too - not surprisingly, in view of the close kinship between these functions. I shall confine myself here to reporting a few carefully analyzed examples and shall make no attempt to cover every aspect of the phenomena [8]. Writing activity, on very basis motion, is to pull out all of things that the writer already absorbed in a very tricky way, contains the emotion and interpersonal perspective. This tricky that the writer plays on while writing is to put himself as far as possible to not directly say 'hi it is me' to the readers. Somehow, while doing such activity the, writer would be sinking into it and let himself to go on with his flow and realize something, both along the activity or when it 
is done. In doing writing activity, writer would be thinking that he is using his full consciousness, but somehow in the aftermath found that he led by his unconsciousness. It means that the writing consists of his true voice. This hidden true voice is the treasure that the researcher tries to dig upon, in this case, the slip of the pen in order to find one of the true voices of Wilde. The psychopathology of everyday life become one of Freud's most popular books. It is concerned with the famous 'Freudian slip'; that is, with slip of the tongue, slip of the pen, faulty recall of names, forgetting of intentions, and other errors. Freud strives to support his belief that all mental events are casually determined by demonstrating that such mistakes or 'parapraxes' are the result of interference by repressed, unconscious thoughts (Storr, 2001:82).

\section{Conclusion}

From his writing, the happy Prince and The Other Tales, it is found that Wilde did the slip of the pen - based on Freud's writing his idea - in two typical of slips itself, symptom number (6) and (18). For symptom number 6, through his writing Wilde did the realization in his own writing while he was tried to show the great sense of love and kindness in The Happy Prince, but ended the story by shading the love itself with 'little better than a beggar'. Then, in the next three stories Wilde then frankly told the silly thing about love and briefly explains how then love decided to be a silly and illogic thing in world. Through these for stories of Wilde, the symptom number 18 about the repetition. Wilde might did not type the repetition of one word, but it happens that he did the repetition of the idea on silly thing about love with various kind of stories and ways in saying it.

\section{References}

[1] J. Culler, Literary Theory-A Very Short Introduction. Great Britain: Oxford University Press, 2000.

[2] N. Haslam, "Freudian Slip? A Changing Cultural Fortunes of psychoanalytic Concepts. Frontiers in Psychology," 2019. [Online]. Available: mendeley.com . [Accessed: 26-Dec-2019].

[3] M. Alder, "Slip of the Tongue as Opportunity for Empathy the Reversed Directedness of 'Project' by A Patient and Her Therapist," 2016. [Online]. Available: mendeley.com. [Accessed: 26-Dec-2019].

[4] Skues, "On the Dating of Freud's Aliquis Slip," 2001. [Online]. Available: mendeley.com . [Accessed: 26-Dec-2019].

[5] Sharpe, "To Slip, perchance to Dream; Freud on the Unconscious," 2013. .

[6] Dimen, "Lapsus Linguae, or A Slip of the Tongue?," 2011. [Online]. Available: mendeley.com . [Accessed: 26-Dec-2019].

[7] M. M. Bakhtin, The Dialogic Imagination. Texas: University of Texas Press, 1988.

[8] S. Freud, Freud-The Psychopathology of Everyday Life. Great Britain: Penguin Books, 1987. 